\title{
Soil properties and the distribution of the endangered Juliana's golden mole
}

C. R. Jackson ${ }^{1}$, N. R. Lubbe ${ }^{2}$, M. P. Robertson ${ }^{3}$, T. H. Setsaas ${ }^{4}$, J. van der Waals ${ }^{5}$ \& N. C. Bennett ${ }^{1}$

1 Department of Zoology and Entomology, Mammal Research Institute, University of Pretoria, Pretoria, South Africa

2 Department of Geography, Geoinformatics and Meteorology, University of Pretoria, Pretoria, South Africa

3 Department of Zoology and Entomology, University of Pretoria, Pretoria, South Africa

4 Department of Biology, Norwegian University of Science and Technology, Realfagbygget, Trondheim, Norway

5 Department of Plant Production and Soil Science, University of Pretoria, Pretoria, South Africa

Correspondence

Craig R. Jackson, Department of Zoology and Entomology, Mammal Research Institute, University of Pretoria, Pretoria 0002, South Africa. Tel: +47 95783090; Fax: +27124203210

Email: crjackson@zoology.up.ac.za

\section{Abstract}

The endangered Juliana's golden mole Neamblysomus julianae occurs in three small, geographically isolated populations within South Africa. As a sand-swimmer, it is a habitat specialist and has a highly fragmented distribution within each population. There is a need for a conservation action plan for this species, but this is difficult because of the dearth of knowledge of its biology, including its habitat characteristics. To better understand its patchy distribution, we selected 48 plots that were occupied or unoccupied by golden moles and measured the soil properties in each plot. The size distribution of sand particles influenced the density and compactability of the soil, and both were positively correlated with the presence of golden moles. These soil characteristics are thus vital in understanding and describing the distribution of this cryptic species.

\section{Introduction}

The golden moles (Chrysochloridae) are a highly specialized mammalian family endemic to sub-Saharan Africa, with 17 of the 21 species occurring in South Africa (Bronner \& Bennett, 2005). Members of this ancient group are totally fossorial, habitat specific and range restricted on account of their acute adaptations to specific soil conditions (Bronner, 1997; Bronner \& Bennett, 2005). When tunnelling, these animals form tiny ridges of soil that often serve as the only evidence that they are 
present. Most species are consequently very cryptic and it is plausible that several golden mole populations and potentially new species are still to be described. Indeed, in the past three years, our research team and collaborators have discovered three new populations of different golden mole species. Golden mole's evolutionary adaptations to their subterranean niche threaten them indirectly in today's anthropogenically transformed world, where their natural soil environment is frequently fragmented and destroyed. The destruction and fragmentation of natural habitat has resulted in 10 of the golden mole species being listed as threatened on the IUCN Red List (Bronner, 2006). Of these, five are critically endangered and are ranked among the 10 most endangered mammals in South Africa (IUCN, 2004).

In South Africa, the cryptic habits of Juliana's golden mole Neamblysomus julianae resulted in it only being described in 1972 from a specimen on the Bronberg Ridge (BR) east of Pretoria (Meester, 1972), and subsequently from Nylsvley Nature Reserve (NNR) $120 \mathrm{~km}$ to the north and the Kruger National Park (KNP) $350 \mathrm{~km}$ to the east (Fig. 1; Bronner, 1997). The Juliana's golden mole is listed as the second most endangered golden mole after De Winton's golden mole Cryptochloris wintoni and has the unenviable reputation of being South Africa's third most endangered mammal (IUCN, 2004).

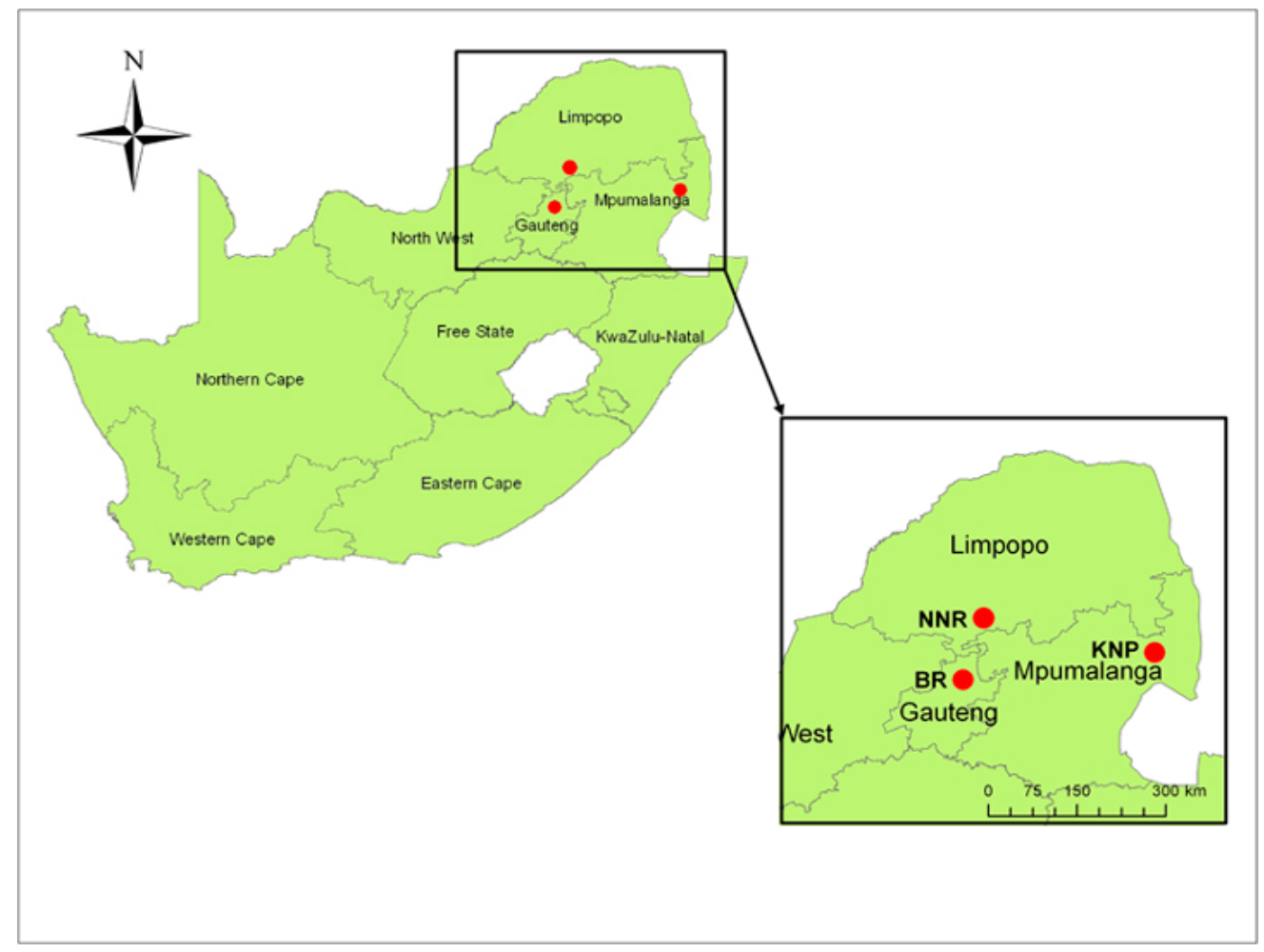

Figure 1. A map of South Africa and its nine provinces showing the distribution of the three isolated populations of Juliana's golden mole Neamblysomus julianae. The populations are described from the Bronberg Ridge (BR), Nylsvley Nature Reserve (NNR) and the southwestern Kruger National Park (KNP). 
As this species is fossorial, many aspects of its general biology and ecology are directly affected by the properties of the soil substrate. To date, literature pertaining to the species distribution states that the Juliana's golden mole is confined to sandy soils (Skinner \& Smithers, 1990), although the animals are not uniformly distributed throughout their geographical range and appear to be restricted to particular habitat types (C. R. Jackson, 2004 pers. obs.). Sand is composed of particles ranging from 0.05 to $2 \mathrm{~mm}$ in size (Brady \& Weil, 2002). The proportions of the various particle size classes within sand samples determine its properties, such as potential compactability and drainage (Brady \& Weil, 2002). The analysis of particle size distribution could thus yield valuable insights into the factors affecting soil suitability for golden moles. A well-graded soil refers to the constituent particles being distributed over a wide range of sizes and, conversely, a poorly graded soil refers to the size of particles being distributed over a narrow size range, thereby having a peak in distribution. Poorly graded soils do not compact significantly whereas well-graded soils compact more readily due to the availability of particles of various sizes to interlock with one another.

The high energetic costs of movement underground have been well documented for subterranean mammals (e.g. Nevo, 1979; Vleck, 1979, 1981; Lovegrove, 1989; Bennett \& Faulkes 2000; Luna, Antinuchi \& Busch, 2002; Luna \& Antinuchi, 2006). The relationship between the cost of tunnelling and soil hardness is regarded as one of the most important factors affecting burrowing efficiency in subterranean rodents (Luna \& Antinuchi, 2006). For example, the digging metabolic rate (DMR) for Ctenomys talarum (Ctenomyidae) was found to be $295.9 \%$ higher than the resting metabolic rate when digging through relatively soft soil (Luna et al., 2002). When confronted with harder soil types, the DMR increased by $66 \%$ (Luna \& Antinuchi, 2006). Similar sharp increases in metabolic rate could be expected for Chrysochlorids. Golden moles living in sandy soils are said to 'sand swim' because they pull and push their way through the sand without actively chiselling away at a soil surface (true burrowing). Unlike the majority of golden moles, the Namib Desert golden mole Eremitalpa granti namibensis often moves above ground before reverting to subsurface sand swimming. The gross energy cost of sand swimming in this species was found to be 26 times more expensive than running on the surface (Seymour, Withers \& Weathers, 1998). Sand swimming, however, only incurred energetic costs amounting to less than one-tenth of the energy required by mammals tunnelling through compact soils (Seymour et al., 1998).

As part of a greater study aimed at identifying the habitat features associated with Juliana's golden mole, our study investigated soil texture and soil penetration resistance (analogous to hardness and bulk density) at sites of all three populations. Our a priori prediction was that the presence of Juliana's golden would be associated with poorly graded soils that would also result in softer substrates, while well graded harder soils would be typical of study plots lacking evidence of golden mole activity.

\section{Methods}

During the summer rainfall months of January-March 2005, data on various soil properties were collected in 48 study plots from the three different populations (KNP $n=23$, golden moles present $=10$; NNR $n=12$, present $=7$; $B R n=13$, present $=9$ ). Each 
plot measured $5 \times 5 \mathrm{~m}$ and was a minimum of $100 \mathrm{~m}$ from other plots. The presence or absence of the species was recorded in each of these plots. Failure to detect the presence of a species in an occupied habitat patch is a common sampling problem when the population size is small, individuals are difficult to sample or sampling effort is limited (Gu \& Swihart, 2004). Additionally, not all suitable habitat is occupied. Detecting the presence of N. julianae is difficult because of the animal's cryptic lifestyle. Only when signs of burrowing are evident can the habitat suitability be known for certain. Ecological data provided for the presence sites in this study are therefore guaranteed to be an accurate reflection of habitat conditions associated with the species distribution. Certain plots where the species is considered to be absent may have been patches of unoccupied but suitable habitat or a patch in which the presence of the animal went undetected. However, all plots were carefully searched to ensure that if the animal was present it was detected, and we are confident that our surveys were accurate. Despite certain limitations, this method is suitable for investigating habitat preferences of the species.

Four soil samples were collected at each plot by means of an auger $(80 \mathrm{~mm}$ in diameter) that extracted soil from the first $200 \mathrm{~mm}$ of the soil profile. After drying the soil samples in an oven, a representative $500 \mathrm{~g}$ subsample from each plot was vibrated through a series of nine sieves for a period of $10 \mathrm{~min}$. Individual sieve contents were weighed and the relative proportions of the sample were calculated, thereby providing the particle size distribution of each sample. A penetrometer (Eikelkamp Agricultural Instruments, Geisbeek, the Netherlands), consisting of a rigid cone-tipped rod attached to a pressure-measuring device (proving ring), was used to determine soil hardness (Herrick \& Jones, 2002). During testing, the penetrometer was pushed vertically into the ground at a slow, steady speed. Measurements assess soil hardness at 50-mm intervals, beginning at the ground surface, and the units of measurement were $\mathrm{kN} / 50 \mathrm{~mm}$. Values for the first $100 \mathrm{~mm}$ (i.e. two values) were analysed because this fraction of the soil profile is where most golden mole activity occurs (Bronner \& Bennett, 2005).

We used Shannon's heterogeneity index $(\mathrm{H})$, which accounts for both abundance and evenness of the particle sizes (Smith \& Smith, 2003). The proportion of particle sizes $i$ relative to the total number of particle sizes $\left(\mathrm{p}_{\mathrm{i}}\right)$ is calculated, and then multiplied by the natural logarithm of this proportion $\left(\ln \mathrm{p}_{\mathrm{i}}\right)$. The resulting product is summed across particle sizes, and multiplied by -1 :

A low Shannon's index value indicates that the majority of soil particles are of a similar size, or poorly graded. Soil hardness is presented as median \pm sd for absence and presence sites. Non-parametric Mann-Whitney U-tests were used to test for differences between presence and absence sites for soil hardness (penetrometer) and for Shannon's index. Spearman's rank correlation analysis was used to test for a correlation between Shannon's index and soil hardness. A significance level of $\mathrm{P}<0.05$ was selected for all tests.

\section{Results}

Shannon's heterogeneity index showed significantly lower values at sites where Juliana's golden mole was present compared with sites where it was absent, $1.66 \pm 0.17$ 
versus $1.90 \pm 0.11$, respectively (Mann-Whitney $\mathrm{U}$-test, $\mathrm{U}=62.0, \mathrm{n}=44, \mathrm{P}<0.0001$ ). Thus, the soil particle sizes were more uniform or more poorly graded in soils where we found golden moles (Fig. 2).

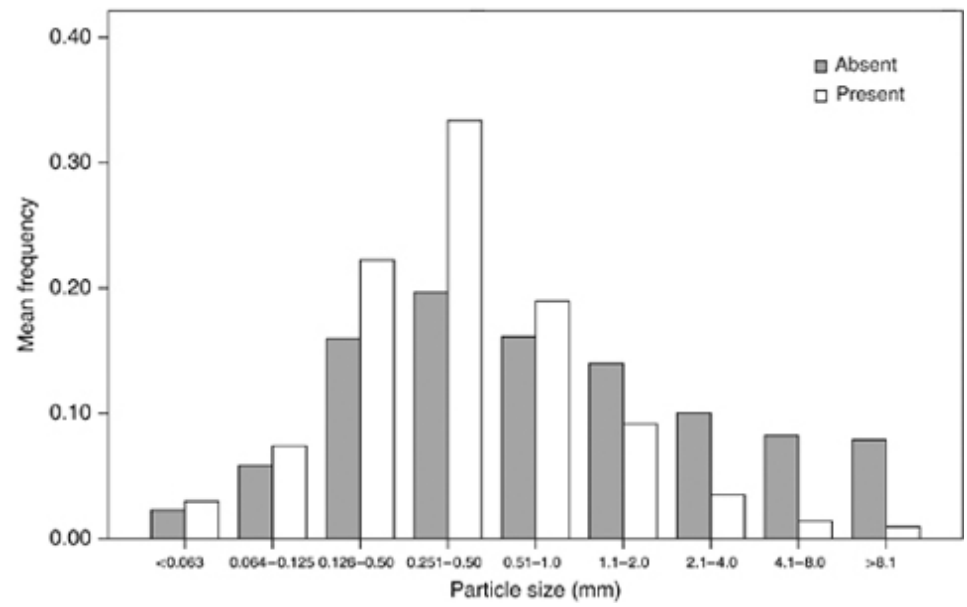

Figure 2 Mean frequency distribution of soil particle sizes (all three study areas combined) from soil samples collected where the golden mole Neamblysomus julianae was either absent $(n=22)$ or present $(n=26)$. Particle size is measured in millimetres $(\mathrm{mm})$.

Soil resistance to the penetrometer probe over the first $100 \mathrm{~mm}$ of the soil profile was $0.49 \pm 0.31$ and $1.05 \pm 0.48 \mathrm{kN} / 50 \mathrm{~mm}$ for presence and absence sites, respectively (Fig. 3). The soil was significantly harder in sites with no signs of golden moles, that is absence sites (Mann-Whitney U-test, $\mathrm{U}=132.0, \mathrm{n}=48, \mathrm{P}=0.001$ ).

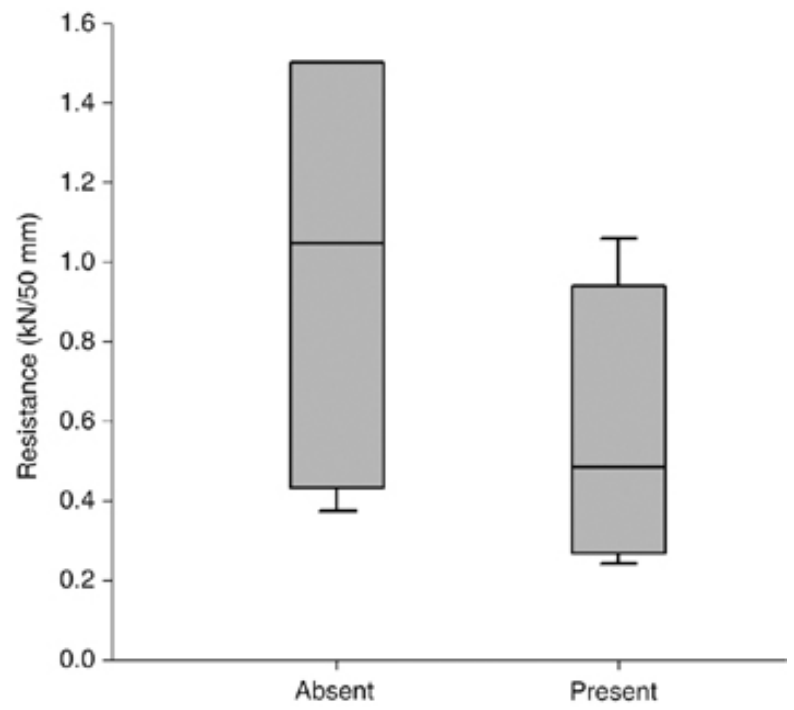

Figure 3 Soil resistance $(\mathrm{kN} / 50 \mathrm{~mm})$ for the first $100 \mathrm{~mm}$ of the soil profile where golden moles were recorded as either absent $(n=22)$ or present $(n=26)$. The shaded boxes incorporate the interquartile range, with the whiskers representing the 10th and 90th percentiles, respectively. The median is indicated within the box plot.

Furthermore, a highly significant positive correlation was found between soil particle size and soil hardness (Spearman's rank, $\mathrm{R}=0.628, \mathrm{n}=44, \mathrm{P}<0.0001$ ). 


\section{Discussion}

Particle size influences several soil properties including soil density and compactability. The particle size distribution data revealed that the sandy soils inhabited by Juliana's golden mole were poorly graded compared with the sites where golden mole activity was not found (Fig. 2). The differences in particle size distribution between the sites led to a difference in the natural bulk density of the surface soil horizons and this difference contributes to the distribution of the golden moles. This property is especially relevant given the small size $(35 \mathrm{~g}$ and $100 \mathrm{~mm}$ in length) of the golden mole and the anatomical adaptations that result in them having relatively weak digging capabilities [compared with the mole-rats (Bathyergidae) e.g.; see Bennett \& Faulkes, 2000] as well as their 'sand swimming' mode of locomotion (Seymour \& Seely, 1996). A poorly graded soil (and therefore a soil with a comparatively low natural density) would thus offer less resistance to tunnelling activities and the animals would expend far less energy on this task (see Seymour et al., 1998). The soil penetrometer values provide a clear indication of the variation in soil bulk density. In this investigation, it was clearly shown that Juliana's golden moles favoured softer soil substrates (Fig. 3), offering significantly less resistance to burrowing activities. Furthermore, the observed pattern of habitat suitability may be additionally influenced by other variables that are difficult to assess, such as food availability, but these may be secondary in importance when compared with the above-mentioned soil properties.

The two Australian marsupial mole species, Notoryctes caurinus and Notoryctes typhlops, are extremely convergent with the Chrysochloridae, and like the Juliana's golden mole, are confined to sandy areas (Johnson, 1995). The striking morphological and ecological similarities of the two groups, including the range restriction associated with soil types, hint at the importance of the soil substrate. Additionally, it is interesting to note that of the 17 species of golden mole that occur within South Africa, nine have distributional ranges that incorporate some part of the coastline (Bronner \& Bennett, 2005). Typical beach and coastal dune sand is also poorly graded and will consequently be less prone to compaction, providing similar advantages to these species.

\section{References}

- Bennett, N.C. \& Faulkes, C.G. (2000). African mole-rats: ecology and eusociality. Cambridge, UK: Cambridge University Press.

- Brady, N.C. \& Weil, R.R. (2002). The nature and properties of soils. 13th edn. New Jersey, USA: Prentice Hall.

- Bronner, G.N. (1997). Species account: family Chrysochloridae. In The complete book of southern African mammals: 54-61. Mills, G. \& Hes, L. (Eds). Cape Town, SA: Struik Publishers.

- Bronner, G.N. (2006). Neamblysomus julianae. 2006 IUCN Red List of threatened species. IUCN 2006 (http://www.iucnredlist.org). (Accessed on 30 December 2006). 
- Bronner, G.N. \& Bennett, N.C. (2005). Sub-editors of golden moles (Chrysochloridae). In The mammals of the southern African subregion. 3rd edn: 1-21. Skinner, J.D. \& Chimimba, C.T. (Eds). Cambridge, UK: Cambridge University Press.

- Gu, W. \& Swihart, R.K. (2004). Absent or undetected? Effects of nondetection of species occurrence on wildlife-habitat models. Biol. Conserv. 116, 195-203.

- Herrick, J.E. \& Jones, T.L. (2002). A dynamic cone penetrometer for measuring soil penetration resistance. Soil Sci. Am. J. 66, 1320-1324.

- IUCN (2004). Red Data Book of the mammals of South Africa, a conservation assessment. South Africa: CBSG Southern Africa, Conservation Breeding Specialist Group (SSC/IUCN), Endangered Wildlife Trust.

- Johnson, K.A. (1995). Marsupial mole. In The mammals of Australia: 409411. Strahan, R. (Ed.) Sydney, Australia: Reed Books.

- Lovegrove, B.G. (1989). The cost of burrowing by social mole-rats (Bathyergidae) Cryptomys damarensis and Heterocephalus glaber: the role of soil moisture. Physiol. Zool. 62, 449-469.

- Luna, F. \& Antinuchi, C.D. (2006). Cost of foraging in the subterranean rodent Ctenomys talarum: effect of soil hardness. Can. J. Zool. 84, 661-667.

- Luna, F., Antinuchi, C.D. \& Busch, C. (2002). Digging energetics in the South American rodent Ctenomys talarum (Rodentia, Ctenomyidae). Can. J. Zool. $80,2144-2149$.

- Meester, J. (1972). A new golden mole from the Transvaal (Mammalia: Chrysochloridae). Ann. Transvaal Mus. 28, 35-46.

- Nevo, E. (1979). Adaptive convergence and divergence of subterranean mammals. Annu. Rev. Ecol. Syst. 10, 269-308.

- Seymour, R.S. \& Seely, M.K. (1996). The respiratory environment of the Namib desert golden mole. J. Arid Env. 32, 453-461.

- Seymour, R.S., Withers, P.C. \& Weathers, W.W. (1998). Energetics of burrowing, running, and free-living in the Namib desert golden mole (Eremitalpa mamibensis). J. Zool. (Lond.) 244, 107-117.

- Skinner, J.D. \& Smithers, R.H.N. (1990). The mammals of the southern African subregion. 2nd edn. South Africa: University of Pretoria.

- Smith, R.L. \& Smith, T.M. (2003). Elements of ecology. 5th edn. San Francisco, USA: Benjamin Cummings.

- Vleck, D. (1979). The energy cost of burrowing by the pocket gopher Thomomysbottae. Physiol. Zool. 52, 122-125.

- Vleck, D. (1981). Burrow structure and foraging costs in the fossorial rodent, Thomomysbottae. Oecologia 49, 391-396. 